\title{
Factors Influencing Girls' Primary Enrolment in Pakistan
}

\author{
Imran Ashraf Toor and Rizwana Parveen*
}

The target set in the National Policy on Education (1998-2010) for primary level enrolment is $90 \%$ of the children of age group of 5-9. This again was an achievable target, provided the available resources were efficiently used and programme interventions were made in a timely fashion. But during the last five years, it has not been implemented effectively and efficiently due to rapid population growth, insufficient political will, a period of undemocratic governance, and poor management of scarce resources. Women and girls have been most affected by these negative factors. The national literacy rate for females is only $35 \%$, compared to $59 \%$ for males, and in certain status the female literacy, enrolment and achievement rates are much lower. There are many issues related to low enrolment of females such as poverty and economic issues, inadequate school infrastructure, gender bias in content and teaching and learning processes and poorly qualified teachers. The analysis of the study indicates that the age of the child, parents' schooling particularly the mother, income per capita of the household head and distance to school are relevant variables in explaining the probability of female enrolment at the primary school level.

\section{JEL Classification: 122.128 and 138}

\section{Introduction}

Education is an essential tool for Human Resource Development and a necessary ingredient for sustainable socio-economic growth. The challenges of the $21^{\text {st }}$ Century could be faced through identifying issues, developing strategies and operational programmes in the education sector. Education, especially female primary education helps reduce poverty by increasing the productivity of the poor, by reducing fertility and improving health, and by equipping people with the skills they need to participate fully in society.

\footnotetext{
* The authors are Economist at Social Policy and Development Centre, Karachi and Lecturer at P.A.F. Degree College Faisal, Karachi. The views expressed are those solely of the authors. Responsibility for all errors lies with the authors.
} 
There are several reasons for the low levels of female enrolment in Pakistan, not the least of which is the high level of poverty. Over one-third of the population is estimated to be living below the poverty line (PIHS-2001$02)^{1}$. According to the new official poverty line, it is inferred that the incidence of poverty is higher in rural areas as compared to urban areas which are 38.7 and 22.4 respectively ${ }^{2}$. Although school attendance is subsidised, the costs of books, uniforms, and transportation to school can be too much to bear for poor families. Poor families are also more likely to keep girls at home to care for younger siblings or to work in family enterprises. If a family has to choose between educating a son or a daughter, because of financial restrictions, typically the son will be chosen. Negative parental attitudes toward educating daughters can also be a barrier to a girl's education. Many parents view educating sons as an investment because the sons will be responsible for caring for aging parents. On the other hand, parents may see the education of daughters as a waste of money because daughters will eventually live with their husbands' families, and the parents will not benefit directly from their education. Also, daughters with higher levels of education will in all likelihood have higher dowry expenses, as they will want a comparably educated husband. However, education sometimes lowers the dowry for a girl because it is viewed as an asset by the husband's family.

Another barrier to female education in Pakistan is the lack of adequate school facilities (PIHS 2000-01). Many rural areas simply do not have classrooms to accommodate all the school-age children. Furthermore, the classrooms that are available often lack basic necessities such as sanitary facilities or water. Lack of 1atrines can be particularly detrimental to girls' school attendance. Lack of female teachers is another potential barrier to girls' education. Girls are more likely to attend school and have higher academic achievement if they are taught by female teachers. Again there are differences among the provinces; the provinces with the highest literacy rates are also the provinces with the highest proportion of female teachers. Many parents, especially in large families with limited resources enroll boys in school instead of or before girls. According to the PIHS 2001-02, 17 percent of girls left school owing to lack of permission from their parents. Some parents also keep their daughters out of school due misinterpretation of the tenets of Islam. Sometimes, students are not motivated to become educated due to the lack of awareness about education (PIHS 2001-02).

\footnotetext{
${ }^{1}$ Pakistan Integrated Household Survey (2001-02).

${ }^{2}$ Economic Survey 2002-03, Finance Division, Government of Pakistan.
} 


\section{Government Priorities for Gender Education}

Gender disparity in primary and secondary education exists in Pakistan. Eliminating gender gaps in basic education/literacy is the cornerstone of the Government of Pakistan policy for social development in general and education in particular. The Ministry of Education has a policy framework in place to advance gender equality in its Education Sector Reforms (ESR) and Education For All (EFA) Programmes. Diverse programmes and strategies have been developed, ranging from compensatory programmes such as stipends at the middle and secondary levels, free textbooks and school nutrition support to girls' schools. Initiatives in Public Private Partnerships such as the school upgradation programme in the afternoons has resulted in a higher coverage for girls at middle, secondary and higher secondary levels. Of the 6240 schools upgraded in the Punjab province and NWFP province, 3787 or $60.8 \%$ are girls schools, and $18 \%$ are mixed schools. ${ }^{3}$ The programme is an outstanding example of addressing gender equity in Pakistan for non-elite groups. In the NWFP province, of the total 93 upgraded institutions, $80 \%$ are girls and mixed schools. Furthermore all $50 \%$ development allocations are being provided to girls schools. It is estimated that during 2002-03 female gross participation rate at the Primary level will increase from $72 \%$ to $76 \%$.

The rest of the paper is organised as follows: Section III presents the literature review. Section IV illustrates the specifications of a model of child schooling and Section V discusses data sources. Section VI is devoted to a discussion of the results. The final section provides the principal findings and policy recommendations.

\section{Literature Review}

There is a vast literature on primary education in LDCs which seeks to find the importance of primary education and the importance of primary schooling as an input to the social and economic progress of poor countries. ${ }^{4}$ The relative importance of school supply versus household demand factors remains controversial, with serious implications for education policy [Simmons and Alexander (1978)]. There have been several papers which look at the household demand for schooling (Deolalikar, 1993; Tanse1, 1993: Sather and Lloyd, 1993; Singh, 1992), due in part to the increasing number of household surveys available in developing countries.

\footnotetext{
${ }^{3}$ Economic Survey 2002-03, Finance Division, Government of Pakistan

${ }^{4}$ Within the overall policy goal of raising primary school enrolment, raising girls' enrolment has received special attention, due to the large positive externalities of female education on children and adult health, fertility and infant mortality.
} 
Many studies of the determinants of school enrolment exist for Pakistan, but they are hardly comparable because of wide differences in data and methodology. Some authors are content with cross-tabulation while others use more sophisticated probit or logit models. Chishti and Lodhi (1988) reveal that the decision to attend school depends on the gender of the potential student, household income, parents' education, and ethnic background. Hamid (1993) uses cross-tabulation to study the distribution of households sending their children to school from various variables of interest such as household income, household heads' profession, education, and gender. Sathar and Lloyd (1994) find that children with educated parents and higher household consumption level attend primary school, though their chances in rural areas are improved with availability of girlsonly public schools within a distance of one kilometer.

Burney and Irfan $(1991,1995)$ included a community variable which is a salient feature of their studies as compared to other studies which are conducted in this area. They found a positive and significant relationship between village literacy level and school enrolment. Alderman et al. (1996) present some probit estimates for school attendance in Pakistan. They find that travel to school and book costs are important influences on the decision to start schooling. Other variables that figure in their school attendance of middle school, a quadratic in age, and square of a measure of preschool ability.

The present study is focused only on female primary school enrolment in Pakistan. It provides inter-region and inter-provincial analysis. Two main questions are addressed in this study: (1) what is the role of family background variables such as income and parental education in the demand for female education? (2) Are household factors affecting education different for region and province for females? These questions are motivated by the particular social and economic environment in the country. This persistent inequality in the face of the historic commitment to public education raises the important question of the impact of education in enhancing social mobility in Pakistan. Moreover, the provincial governments have recently introduced 'cost-sharing' in its primary education policy which has aimed to target the poor and deprived areas. There is a gap between male and female enrolment in Pakistan, which increases by age group. It is therefore of special interest to separately investigate and compare the determinants of schooling demand for girls. 


\section{Model And Empirical Approach}

\section{A. Theoretical Model}

Parents' decision to educate their children, or invest in human capital formation, has often been analysed in a Chicago-Columbia framework.' Therefore, the demand for children's education can be derived from a Becker-Lewis model of household production where it is assumed that parents or elders make decisions regarding child schooling. A simple version of the household's problem is to maximise

$$
\mathrm{U}(\mathrm{X}, \mathrm{Z})
$$

Subject to

and
$\mathrm{P}_{\mathrm{x}}{ }^{\wedge} \mathrm{X}+\mathrm{W}^{\wedge} \mathrm{L}=\mathrm{W}^{\star} \mathrm{T}+\mathrm{Y}$

(2)

$\mathrm{Z}=\mathrm{Z}(\mathrm{X}, \mathrm{t} ; \Omega)$

In this framework household utility (1) is maximised over market (X) and non-market $(Z)$ goods, subject to a full income constraint (2) and a household production function for non-market goods (3). Inputs to the production function are time $(\mathrm{t})$ and market goods, as well as an efficiency parameter $(\Omega)$ which depends on factors such as the ability or experience of household workers, access to complementary public inputs and so on. Market goods are purchased at price $P_{x}$ household time endowment is $T$, unearned income is $\mathrm{Y}$, the wage rate is $\mathrm{W}$ and leisure consumption $\mathrm{L}$.

The outcomes measured in this study are Z-goods, and solving the household problem yields demand functions that relate the optimal level of their consumption to the exogenous variables: prices, unearned income, household efficiency $(\Omega)$ and preferences. We use this framework to guide the choice of explanatory variables - thus the demand for schooling will be an increasing function of the perceived benefits of schooling, and a decreasing function of its costs (both direct and opportunity costs). Household characteristics that increase the costs (or decrease the benefits) of educating a child will lower the household demand for education.

\footnotetext{
${ }^{5}$ For details, the readers are referred to Becker and Lewis (1973); Becker and Tomes (1976) and DeTary (1973).
} 
In this framework, parents' education and socio-economic status are considered to have a significant impact on child schooling. For example, in many empirical studies, the mother's schooling is found to be positively associated with child schooling in the market and household activities. ${ }^{6}$ Within the Chicago-Columbia framework, much of the work on child schooling has been done in the context of fertility behaviour. A few researchers, however, have also attempted to analyse child schooling per se. The studies by King and Lillard (9183) and DeTary and Rindfuss (1983) are some of the examples.

\section{B. Empirical Approach}

The outcome representing the demand for education is considered in this study. We analyse the probability of currently enrolled females in primary school. The dependent variable is dichotomous, so the logistic function is used to fit the data.

There are two categories of independent variables - individual specific and household specific. The former include age and its square. The age variable reports the age of the girl which is 5-10 years. The other variables are parent's education, while the latter are gender of household head, number of residents 0-5 years age in the house, number of resident 5-10 years age in the house, two regional dummies (region and province), distance to school which represents the time cost of school attendance, and (log of) total per capita household expenditure, persons per room and electricity in the house. All regressions are estimated separately for females by region and province wise.

\section{Data Description}

The data used in the estimation come from the fourth round of the Pakistan Integrated Household Survey 2001-02 (PIHS). The PIHS survey consists of about 16,182 households. This survey is stratified by province (Punjab, Sindh, NWFP and Balochistan) and by region urban/rural area. Households residing in different parts of the country have been selected for the PIHS survey using the stratified sampling technique. In order to derive representative statistics for each of the provinces, as well as for the country as a whole, raising factors are applied. These raising factors take into account the sampling strategy adopted in the survey and weigh each household by a factor that is inversely proportional to its probability of selection. There is detailed information on the educational status of

6 In the alternative 'Pennsylvanian' model, this is interpreted to reflect an intergenerational effect rather than the productivty effect of educated parents. This implies that the parents' schooling in the Pennsylvanian model does not have as large a productivity effect as in the Chicago-Columbia framework. 
each household member over five years old, which is merged with the household roster, consumption, and community modules to get the necessary information for the analysis. Variable means for the sample are reported in Table 1.

Table-1: Mean and Standard Deviation of the Variables

\begin{tabular}{lll}
\hline Variables & Mean & Std. \\
\hline Current enrolment & 0.445 & 0.497 \\
Female share in population & 0.491 & 0.500 \\
Age in years & 7.450 & 1.700 \\
Age squared & 58.448 & 25.740 \\
Father's education & 3.562 & 4.774 \\
Mother's education & 2.394 & 6.687 \\
Female Headed Household & 0.064 & 0.245 \\
No. of residents 0-5 year olds & 1.970 & 1.660 \\
No. of residents 5-10 years olds & 2.75 & 1.390 \\
Distance to school (km) & 1.305 & 0.685 \\
Log per capita expenditure & 8.820 & 0.555 \\
Persons per room & 4.457 & 2.402 \\
Electricity in the house & 0.643 & 0.479 \\
\hline
\end{tabular}

Source: Pakistan Integrated Household Survey 2001-02.

\section{Regression Results}

The regression results consisted of two parts. In the first part, we discussed the inter-regional analysis of girls' enrolment in Pakistan. The last part is based on inter-provincial analysis.

\section{A. Regional Impact on Female Enrolment}

Does the impact of family background represent largely unobserved regional level heterogeneity? Table- 2 presents the logistic estimation results of enrolment for females. Households in the urban areas are more flexible in choosing government or private schools for girls' schooling as compared to the households that are in rural areas. When we analysed girls' enrolment in urban and rural areas, we observed that the mother's education was more important as compared to the father's education in both areas. Children whose mothers had more years of schooling had more enrolment than children whose mothers were less educated. Children of educated mothers were more likely to be continuing their education. The results also reflect that mother's education is more important for girls' primary enrolment in rural areas as compared to urban areas. This confirmed the previous study conducted by Handa (1996). 
Per capita expenditure has a positive and significant coefficient. This trend shows that a positive correlation exited between girls' enrolment and per capita expenditure. Arif et al. (1999) also proofed this relationship using the Pakistan Socio Economic Survey (PSES) data set.

To see how girls' enrolment is affected by the household demographic composition, we add two variables to the model: the number of children five years old or younger, and the number of children aged 5-10 year residing in the household. The coefficient on the latter will tell us to what degree households make a 'quality-quantity' trade-off in the schooling decision. Naturally both these variables are endogenous, ${ }^{7}$ so their coefficient estimates should be interpreted as strict partial correlation coefficients without any implication of causality. Numbers of children aged 0-5 and the number of children aged 5-10 have higher elasticities in urban areas as compared to rural areas.

The variable 'persons per room' describes the conjunction in the house and it is related to poverty. Poor families have more conjunction in the house as compared to rich families. This conjunction can add immeasurably to the discomfort and inconvenience in the house. So hypothetically it has a negative relationship with female enrolment. It has a significant sign in this study according to the hypothesis in both areas. The rate of incidence of poverty is higher in rural areas as compared to the urban areas; ${ }^{8}$ so housing infrastructure is poor in rural areas which is reflected in this study. Electricity in the house has a positive relationship with enrolment in both time periods. It has a higher magnitude in the rural areas, which shows that in areas where electricity is available there is more enrolment as compared to those areas where electricity does not yet exist. Electricity in the house provides a comfortable environment for education. Students can use better lighting for study and can use a fan in the summer season to lengthen their study hours.

\footnotetext{
${ }^{7}$ We do not have any instruments to try and correct for this problem.

8 Economic Survey 2002-03, Finance Division, Government of Pakistan
} 
Imran Ashraf Toor and Rizwana Parveen 149

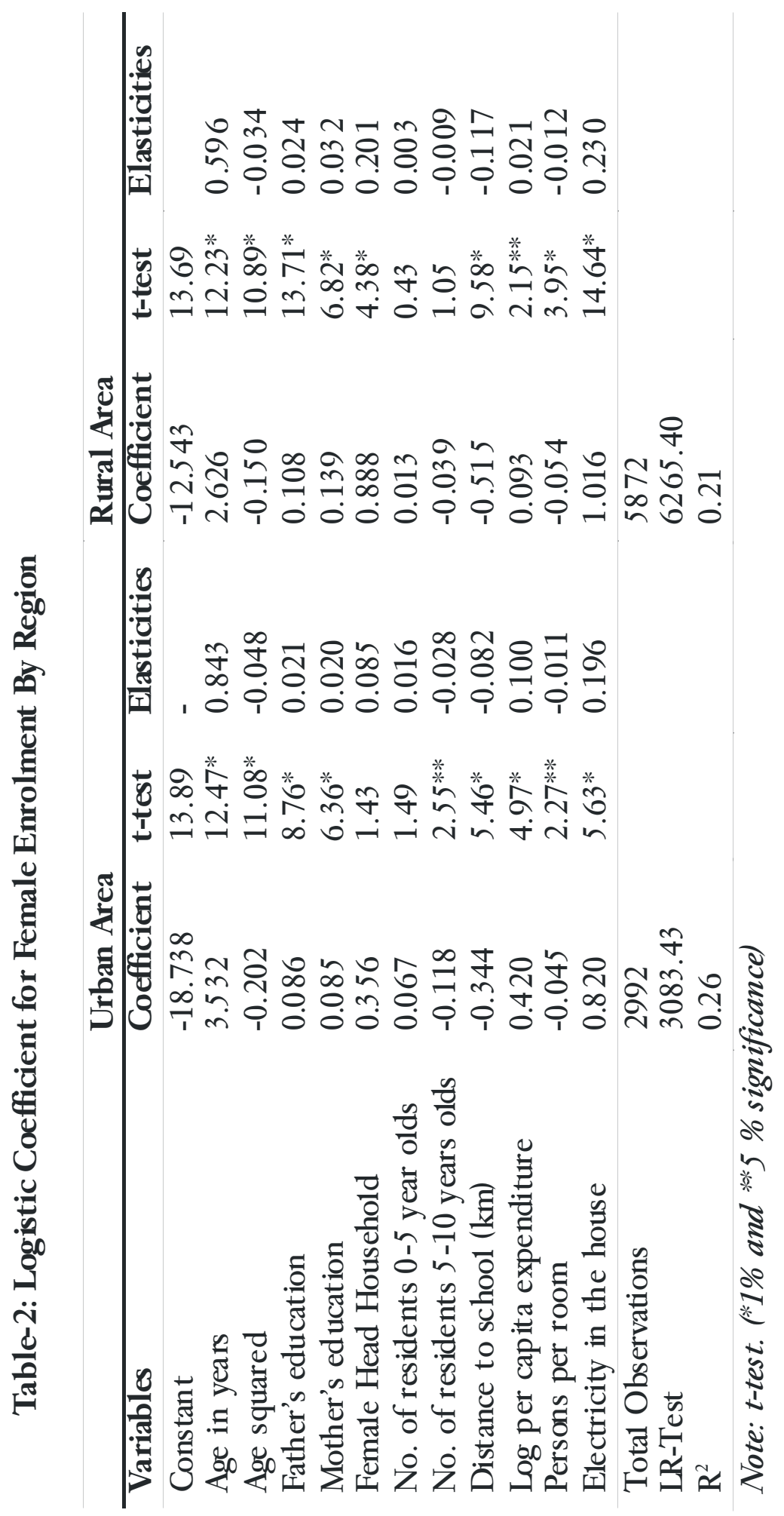


Another important variable is distance to school which has a negative relationship with enrolment in both areas, it has a higher coefficient in rural areas. Children travel to and from their primary schools, even in rural areas, most travel less than $2 \mathrm{~km}$ and very few travel more than $5 \mathrm{~km}$. Girls have to travel long distances to school particularly in the Balochistan and Sindh provinces, where the distances involved would be expected to represent a substantial barrier to access. ${ }^{9}$ This exhibits that school facilities are very poor and out of the access of poor people in rural areas. This is very obvious when the question of rural urban disparity arises. In Pakistan, it is frequently found that school facilities are mostly urban based, particularly in the private sector and rural areas are often taken for granted with respect to the government schools and hence are deprived of their basic rights.

\section{B. Inter-Provincial Differences in Female Enrolment}

Inter-provincial differences in enrolment are displayed in Table-3. Interprovincial analysis has importance for girls' enrolment because the analysis provides us the provincial differences in female primary education. According to estimates, father and mother's education is an important factor in all provinces. The father's education is more important in the Punjab province because the elasticity of this variable is higher in this province as compared to the other provinces. Mother's education has higher elasticity in the NWFP province and the least elasticity in Sindh province.

Table-3: Inter-Provincial Elasticities •

\begin{tabular}{lllll}
\hline Variables & Punjab & Sindh & NWFP & Balochistan \\
\hline Constant & - & - & - & - \\
Age in years & 0.819 & 0.520 & 0.863 & 0.456 \\
Age squared & -0.047 & -0.030 & -0.049 & -0.026 \\
Father's education & 0.027 & 0.020 & 0.025 & 0.019 \\
Mother's education & 0.023 & 0.016 & 0.028 & 0.024 \\
Female Headed Households & 0.187 & 0.271 & 0.077 & 0.155 \\
No. of residents 0-5 year olds & 0.011 & 0.011 & 0.007 & 0.005 \\
No. of residents 5-10 years olds & -0.016 & -0.002 & -0.018 & 0.004 \\
Distance to schoo1 (km) & -0.141 & -0.246 & -0.043 & -0.114 \\
Log per capita expenditure & 0.092 & 0.101 & 0.064 & 0.003 \\
Persons per room & -0.018 & -0.010 & -0.008 & -0.003 \\
Electricity in the house & 0.261 & 0.180 & 0.194 & 0.180 \\
\hline
\end{tabular}

Source: Appendix Table A-1 to A-4 • See Appendix-B

\footnotetext{
${ }^{9}$ Pakistan Integrated Household Survey 2001-02.
} 
The distance to school is significant in all provinces. The elasticity of this variable is higher in the Sindh Province and the lowest in Balochistan Province. This shows that in the Sindh province school facilities are not near to the residence of the people. Similarly, per capita expenditure has higher elasticity in the Sindh province as compared to the other provinces. This trend shows that poverty and enrolment has a positive relationship in this province as compared to the other provinces.

Another important variable 'female headed household' has the highest elasticity in Sindh province which illustrates that a woman who is a head of a household has more influence in the Sindh province for girls' enrolment. The variables persons per room and electricity in the house have higher elasticities in Punjab province as compared to other provinces. This shows that population conjunction has effectiveness in this province. Likewise electricity also has importance due to the provision of better environment in the house for education.

There are also other multiple factors that may cause changes in female enrolment. However, it is plausible to argue that demand side factors, in the case of Pakistan, are mainly responsible for these changes during the last decade. The following hypotheses or suppositions may illustrate the increasing enrolment of girls. Household's human and physical assets and changes in its income significantly affect children's education patterns. Serious supply-side constraints on village girls' primary education suggest the importance of supply-side policy interventions in Pakistan's rural primary education-for example, providing more girls' primary schools close to villages and employing more female teachers. Advocacy for recruitment of a quota of female teachers in rural areas. Social mobilisation campaigns for girls' education in rural areas through television and radio, Imam (religious leader) and interpersonal communication. Technical support of the Ministry of Education and the Textbook Printing Press to review the storage and distribution system, and to suggest improvements.

\section{Conclusions And Policy Implications}

Education has a positive impact on individual earnings and also yields substantial externalities: parents' education and mother's literacy and education are associated with low infant mortality rates, higher enrolment and achievement rates of children and less gender differences in enrolment of children. There are also significant differences across provinces with decline in enrolment in Sindh and Balochistan in public sector education. To increase girls' primary school enrolment is a major development imperative, although the interventions that can best raise enrolment are not always straightforward. 
This paper evaluates the relative importance of supply and demand side factors in determining girls' primary school enrolment.

Socioeconomic background is an important determinant of the demand for primary schooling in Pakistan, and an even more important determinant of enrolment in primary school for girls. School supply also plays a role in influencing enrolment- girls from rural regions or those who live farther away from school are less likely to be enrolled. There are important differences in the demand for schooling by gender. School availability also has a significant impact on enrolment rates. Reducing the travel distance to the nearest school will increase the enrolment rate. Construction of a village will increase enrolment more among poorer households. For enrolment, mother's and father's education is also important for females. Similarly, household income has a much bigger effect on the probability of enrolment.

Despite this awareness, major challenges remain to increase access to education, to improve quality, and to commit resources for the education system to keep pace with the economic structure will most likely hinder Pakistan's economic prosperity. Conversely, timely reforms can pay off in terms of economic growth and poverty reduction, as is evident from the experience of East Asian countries which have generally invested heavily in basic human capital, both male and female.

Having taken steps to ensure that all children can go to school, the government, with help from donor agencies such as UNESCO and UNICEF, must devote equal attention to ensuring that all children can learn. Trained, well-paid teachers, reasonable class sizes, adequate hours of instruction, supplies of books and materials, a child-friendly learning environment and strong mechanisms for community oversight of local schools: these are not just optional add-ons, they are the fundamental ingredients of the process known as "education". Running a school without these essentials is like trying to run a hospital without medicines or doctors. Yet many cash-strapped districts are trying to do exactly that; so it is hardly surprising that they suffer from high drop-out and repetition rates, which eat further into their budgets. National education plans must therefore include priority action to improve and monitor the quality of teaching and learning, especially in the most disadvantaged communities and worst-performing schools, which have often suffered decades of neglect and underinvestment. Special priority must at least triple, and aid to basic education in Pakistan must increase manifold, in order to achieve this goal. 


\section{Appendix-A:}

Table-A-1: Logistic Coefficient for Female Enrolment (Punjab Province)

\begin{tabular}{lccl}
\hline Variables & Coefficient & t-test & Elasticities \\
\hline Constant & -17.257 & 14.39 & \\
Age in years & 3.332 & $11.96^{*}$ & 0.819 \\
Age squared & -0.191 & $10.62^{*}$ & -0.047 \\
Father's education & 0.110 & $9.79^{*}$ & 0.027 \\
Mother's education & 0.092 & $5.49^{*}$ & 0.023 \\
Female Headed Household & 0.759 & $3.39^{*}$ & 0.187 \\
No. of residents 0-5 year olds & 0.046 & 1.00 & 0.011 \\
No. of residents 5-10 years olds & -0.067 & 1.37 & -0.016 \\
Distance to school (km) & -0.573 & $8.85^{*}$ & -0.141 \\
Log per capita expenditure & 0.375 & $6.07^{*}$ & 0.092 \\
Persons per room & -0.073 & $3.79^{*}$ & -0.018 \\
Electricity in the house & 1.063 & $10.38^{*}$ & 0.261 \\
\hline Total Observations & 3292 & & \\
LR-Test & 3438.90 & & \\
$\mathrm{R}^{2}$ & 0.30 & & \\
\hline Note: t-test. (*1\% and ${ }^{* * 5} \%$ significance) & &
\end{tabular}

Table-A-2: Logistic Coefficient for Female Enrolment (Sindh Province)

\begin{tabular}{lccc}
\hline Variables & Coefficient & t-test & Elasticities \\
\hline Constant & -15.037 & 9.61 & - \\
Age in years & 2.577 & $7.96^{*}$ & 0.520 \\
Age squared & -0.149 & $7.07^{*}$ & -0.030 \\
Father's education & 0.098 & $8.60^{*}$ & 0.020 \\
Mother's education & 0.077 & $4.21^{*}$ & 0.016 \\
Female Headed Household & 1.341 & $3.02^{*}$ & 0.271 \\
No. of residents 0-5 year olds & 0.056 & 1.08 & 0.011 \\
No. of residents 5-10 years olds & -0.008 & 0.14 & -0.002 \\
Distance to school (km) & -1.218 & $8.97^{*}$ & -0.246 \\
Log per capita expenditure & 0.500 & $5.03^{*}$ & 0.101 \\
Persons per room & -0.051 & $2.58^{*}$ & -0.010 \\
Electricity in the house & 0.890 & $7.84^{*}$ & 0.180 \\
\hline Tota1 Observations & 2472 & & \\
LR-Test & 3090.58 & & \\
$\mathrm{R}^{2}$ & 0.27 & & \\
\hline
\end{tabular}

Note: t-test. (*1\% and *\%5 significance) 
154 The Labore Journal of Economics, Vol.9, No.2

Table-A-4: Logistic Coefficient for Female Enrolment (NWFP)

\begin{tabular}{lccc}
\hline Variables & Coefficient & t-test & Elasticities \\
\hline Constant & -19.376 & 10.42 & - \\
Age in years & 3.816 & $8.77^{*}$ & 0.863 \\
Age squared & -0.218 & $7.91^{*}$ & -0.049 \\
Father's education & 0.110 & $7.52^{*}$ & 0.025 \\
Mother's education & 0.123 & $3.50^{*}$ & 0.028 \\
Female Headed Household & 0.339 & 1.07 & 0.077 \\
No. of residents 0-5 year olds & 0.030 & 0.55 & 0.007 \\
No. of residents 5-10 years olds & -0.081 & 1.36 & -0.018 \\
Distance to schoo1 (km) & -0.190 & $3.15^{*}$ & -0.043 \\
Log per capita expenditure & 0.282 & $3.45^{*}$ & 0.064 \\
Persons per room & -0.037 & 1.24 & -0.008 \\
Electricity in the house & 0.857 & $5.35^{*}$ & 0.194 \\
\hline Total Observations & 1641 & & \\
LR-Test & 1809.44 & & \\
$\mathrm{R}^{2}$ & 0.25 & & \\
\hline
\end{tabular}

Note: t-test. (*1\% and $*$ *5 \% significance)

Table-A-4: Logistic Coefficient for Female Enrolment

(Balochistan Province)

\begin{tabular}{lccc}
\hline Variables & Coefficient & t-test & Elasticities \\
\hline Constant & -11.871 & 6.02 & - \\
Age in years & 2.449 & $5.44^{*}$ & 0.456 \\
Age squared & -0.138 & $4.79^{*}$ & -0.026 \\
Father's education & 0.104 & $7.61^{*}$ & 0.019 \\
Mother's education & 0.127 & $3.82^{*}$ & 0.024 \\
Female Headed Household & 0.832 & 1.18 & 0.155 \\
No. of residents 0-5 year olds & 0.026 & 0.37 & 0.005 \\
No. of residents 5-10 years olds & 0.020 & 0.28 & 0.004 \\
Distance to school (km) & -0.611 & 3.84 & -0.114 \\
Log per capita expenditure & 0.017 & 0.17 & 0.003 \\
Persons per room & -0.014 & 0.39 & -0.003 \\
Electricity in the house & 0.969 & $6.33^{*}$ & 0.180 \\
\hline Total Observations & 1459 & & \\
LR-Test & 1544.81 & & \\
$\mathrm{R}^{2}$ & 0.20 & & \\
\hline
\end{tabular}

Note: t-test. (*1\% and **5 \% significance) 


\section{Appendix-B:}

The derivation of the elasticities used in Table- 2 and Table- 3 .

$$
\begin{aligned}
& L^{\prime}=\ln \left(\frac{P i}{1-P i}\right)=\beta_{0}^{\wedge}+\beta_{1}^{\wedge} X \\
& \beta_{1}^{\wedge}=\frac{d L}{d X} \\
& \beta_{1}^{\wedge}=\frac{d}{d X}\left[\ln \left(\frac{P i}{1-P i}\right)\right] \\
& \beta_{1}^{\wedge}=\frac{1}{P i} \frac{[1-P i)}{(1-P i}\left(\frac{d X}{d-P i)-P i\left(\frac{-d P i}{d X}\right)}\right] \\
& \beta_{1}^{\wedge}=\frac{1}{P i(1-P i)} \cdot\left(\frac{d P}{d X} \cdot\{1-P i+P i\}\right) \\
& \beta_{1}^{\wedge}=\frac{1}{P i(1-P i)} \cdot\left(\frac{d P}{d X}\right) \\
& \frac{d P}{d X}=\beta_{1}^{\wedge} P i(1-P i) \\
& \text { Elasticity } \frac{d P}{d X} \cdot \frac{X}{P}
\end{aligned}
$$




\section{References}

Arif G.M., Saqib Najam US, and Zahid G.M., 1999, 'Poverty, Gender, and Primary School Enrolment in Pakistan.' The Pakistan Development Review 38:4 Part II (Winter 1999) pp 979-992.

Becker, G. S., and H.G. Lewis, 1973, 'Interaction between Quantity and Quality of Children.' Journal of Political Economy 81: 2, Part 2, S279S288.

Becker, G. S., and N. Tomes, 1976, 'Child Endowments and the Quantity and Quality of Children', Journal of Political Economy 84: 4, Part 2, pp279-162.

Burney, Nadeem A., and Mohammad Irfan, 1991, 'Personal Characteristics, Supply of Schools, and Child School-enrolment in Pakistan., The Pakistan Development Review 30:1 pp 21-62.

Burney, Nadeem A., and Mohammad Irfan, 1995, 'Determinants of Child School Enrolemnt: Evidence from LDCs Using Choice-theoretic Approach., International Journal of Social Economics 22:1 pp 24-40.

Chishti, Salim, and Akhtar Lodhi, 1988, 'Simultaneous Determination of Choice to Attend School, and the Demand for School Education: A Case Study of Karachi, Pakistan. Pakistan Journal of Applied Economics 7: 2 pp 101-108.

Deolalikar, A., 1993, 'Gender Differences in the Returns to Schooling and School Enrolment Rates in Indonesia', Journal of Human Resources, Vol.28, No.4, pp.899-932.

DeTary, D., 1973, 'Child Quality and the Demand for Children', Journal of Political Economy 81:2, Part 2, pp570-595.

King, E.M., and L.A. Lillard, 1983, 'Determinants of Schooling Attainment and Enrolment Rates in the Philippines', The Rand Corporation, N1962-AID, Santa Monica, California.

Sather, Z. and C. Lloyd, 1993, 'Who Gets Primary Schooling in Pakistan: Inequalities Among and Within Families', New York: The Population Council Working Paper No.52. 
Simmons, J., Alexander, L., 1978, 'The determinants of Schooling Achievement in Developing Countries: A Review of the Research.' Economic Development and Cultural Change 26 (2) , pp 341-357 Jan.

Singh, R.D., 1992, 'Underinvestment, Low Economic Returns to Education, and the Schooling of Rural Children: Evidence from Brazil'. Economic Development and Cultural Change, Vo1.40, No.3, pp.645-64.

Tanse1, A., 1993, 'School Attainment, Parental Education and Gender in Cote d'lvoire and Ghana', New Haven, CT: Yale University Economic Growth Center, Discussion paper No.692. 